IRA-International Journal of Management \&

Social Sciences

ISSN 2455-2267; Vol.15, Issue o4 (July-September, 2019)

Pg. no. 142-149.

Institute of Research Advances

http://research-advances.org/index.php/RAJMSS

QUARTERLY

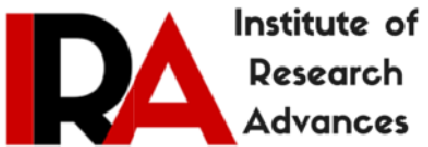

\title{
Information Assurance into Research Level in India: The Case of Possible Research-based Degrees
}

\author{
P. K. Paul ${ }^{1 \#} \&$ P. S. Aithal ${ }^{2}$ \\ ${ }^{1}$ Executive Director, MCIS, Department of CIS, Raiganj University (RGU), West Bengal, India. \\ ${ }^{2}$ Vice Chancellor, Srinivas University, Karnataka, India.
}

Type of Work: Peer Reviewed.

DOl: http://dx.doi.org/10.21013/jmss.v15.n4.p8

\section{How to cite this paper:}

Paul, P.K., Aithal, P.S. (2019). Information Assurance into Research Level in India: The Case of Possible Research-based Degrees. IRA-International Journal of Management \& Social Sciences (ISSN 2455-2267), 15(4), 142-149. doi:http://dx.doi.org/10.21013/jmss.v15.n4.p8

(C) Institute of Research Advances.

\section{(cc) EY-NC}

This work is licensed under a Creative Commons Attribution-Non Commercial 4.0 International License subject to a proper citation to the publication source of the work.

Disclaimer: The scholarly papers as reviewed and published by the Institute of Research Advances (IRA) are the views and opinions of their respective authors and are not the views or opinions of the IRA. The IRA disclaims of any harm or loss caused due to the published content to any party.

Institute of Research Advances is an institutional publisher member of Publishers International Linking Association Inc. (PILA-CrossRef), USA. The institute is an institutional signatory to the Budapest Open Access Initiative, Hungary advocating the open-access of scientific and scholarly knowledge. The Institute is a registered content provider under Open Access Initiative Protocol for Metadata Harvesting (OAI-PMH).

The journal is indexed \& included in WorldCat Discovery Service (USA), CrossRef Metadata Search (USA), WorldCat (USA), OCLC (USA), Open J-Gate (India), EZB (Germany) Scilit (Switzerland), Airiti (China), Bielefeld Academic Search Engine (BASE) of Bielefeld University, Germany, PKP Index of Simon Fraser University, Canada. 


\begin{abstract}
Information Assurance, in short, is also called as IA. The field is concerned with the security of information. However, additionally, it is also responsible for the different kind of contents in a different form. The field Information Assurance is very close to Information Security; however, it also deals with manual contents security. According to the Information Scientist, Information Assurance talks about the rules, regulation, framework designing and development of security of the information or contents. The field Information Technology is growing rapidly and different fields have been incorporated into this viz. Database Technology, Web Technology, Network Technology, Software Technology, Multimedia Technology, etc. The applications of Information Technology into different fields, sectors, areas are called Information Science (IS). This branch is closest to the Society and Community and responsible for Social Development; additionally, it talks about manual information-related activities. Hence, Information Assurance as deals with both Computing and Manual content security, so it is considered as a branch of Information Assurance. Internationally many universities have started degree programs in the field. India also holds a large number of Higher Educational Institutes and offers a variety of UG, PG and Research Degrees. Even in recent past few universities have started some of the specialized PhD and research degrees. But still, there is an absence in Information Assurance academic program in India including PhD Degree. This paper is a kind of theoretical framework in response to the potentiality of PhD and researchbased degrees in the field of Information Assurance and allied areas.
\end{abstract}

Keywords: Information Assurance, IT Security, IT Management, Cyber Security, Data Privacy, Researchbased Degrees, Indian Higher Education, UGC

\title{
Introduction
}

Worldwide the field of Information Technology is changing, there are different areas where a lot of development noted and among these Communication and Networking, Multimedia and Animation, Intelligent Systems play a leading role. Various universities launch programs on different areas of IT and Computing and among these Cyber Security is important and valuable. It is worthy to note that, many universities in India also offered subfields of Information Technology as a full-fledged degree and major [1], [5], [14]. But importantly, among the universities it is little. Information Assurance as a branch is not available in India universities; however few universities have started related programs Cyber Security, IT Security, Information Security. The research degrees in India are normally treated as MPhil and PhD; in all these degrees and in other degrees as well research focused Information Assurance field may be started.

\section{Objective and Agenda}

This is a conceptual paper and a kind of theoretical framework and mainly concerns with the following aim and objectives-

- To learn about the basics of Information Assurance including its features and characteristics.

- To find out the function and need for Information Assurance and thus the academic programs related to the Information Assurance.

- To learn about the existing programs in the field of Information Assurance and allied fields in International Universities.

- To find out the research degrees available in Information Assurance in International universities.

- To find out the Indian Higher Education Systems; with special reference to IT education in the Indian context.

- To prepare some of the possible research degrees in the field of Information Assurance and allied areas. 


\section{Information Assurance: Overview}

The field Information Assurance is interdisciplinary and growing rapidly the area is also skill-based in nature. Emerging technologies viz. Cloud Computing Security, Big Data Security, Mobile and Wireless Security are the core of Information Assurance from its technological side. Information Assurance is managerial in nature and deals with various affairs on policy, regulation, guidelines related to privacy and security [2], [6], [19]. Information Assurance is a combination of Information Security, IT Security. There are different ministries, government and private department's name these days on Information Assurance. Information Assurance is responsible for various activities viz.-

- Information Assurance is technical and managerial in nature and thus solve the issues related to data privacy and information governance.

- The availability of information and content to the right person and in the right form is the need of the hour and Information Assurance fulfils this.

- Information Assurance is a dedicated branch and responsible for technical security related issues viz. database, web and networks and this are emerging [4], [5], [20].

- Information Assurance is responsible for advanced and emerging security solutions and policy framework related to security.

- Traditional documents or contents are emerging and gradually developing; here such contents securities are also important and as a branch Information Assurance is also important [7],[8], [21].

- Information Assurance deals all the affairs leading to cyber-security management and cyber-infrastructure designing and development.

\section{Information Assurance and Allied Education}

From the previous section, it has been already learned that Information Assurance is an advanced, emerging and interdisciplinary area and thus as a result apart from the research areas many universities, internationally have started academic programs on Information Assurance and allied nomenclature leading to Bachelors, Masters Degrees [3], [9], [12], [15]. There are various nomenclatures used in this field viz.

- Information Assurance

- Information Assurance and Cyber Forensic

- Information Security and Assurance

- Cyber Security and Information Assurance

- Information Assurance and Infrastructure Management etc

There are many universities internationally changing their nomenclature from traditional Security related nomenclature to Information Assurance or in the allied field.

\section{India and Education in Computing and Information Field}

In India, Computing and allied subjects are offered with different nomenclature and flavour and this include Computer Science (which deals on the theory and basics of applications for the designing, development and management of computer systems. It is mathematics and deals the core and internal areas of computer), Computer Applications (This is another popular stream focused on software technologies and design and development of applications for the organizations and institutions. The field is less mathematical and mainly available in India), Computer Engineering/ Computer Science and Engineering (This is similar to Computer Science, but special focuses on hardware and applications for software development). Information Technology (This is another area 
which is dedicated to the information solutions with the help of various subfields viz. Web Technology, Database Technology, Network Technology, Multimedia Technology and traditional Software Technologies).

However, apart from these subjects few other nomenclature and concentration may be noticeable and this includes the following-

- Information Science

- Information Systems

- Software Engineering etc.

It is worthy to note that only a few universities offer such program. Here the field Information Science is concentrated on Information related studies and also information solutions, and for this, different IT components are being used. This is also society centric and offers technological and information solution to the society and different sectors [11], [13], [16]. Information Systems is a domain similar to Information Science but mainly concentrated on applications of IT in organizations and business houses with the focus of systems analysis, designing and complete system studies. As noted that IT is composed of different subjects and among these, Software Technology is most common and popular [10], [17], [18]. And thus there is an available branch on Software Engineering in some of the institutes. The following are some of the available degrees and based in Indian universities (refer Table: 1) -

Table: 1-Different computing-related stream with available degrees

\begin{tabular}{|l|l|}
\hline Streams & Degrees \\
\hline Computer Science & $\mathrm{BSc}, \mathrm{MSc}, \mathrm{MPhil}, \mathrm{PhD}$ \\
\hline Computer Engineering/ CSE & $\mathrm{BTech} / \mathrm{BE}, \mathrm{MTech} / \mathrm{ME}, \mathrm{PhD}$ \\
\hline Computer Applications & $\mathrm{BCA}, \mathrm{MCA}, \mathrm{PhD}$ \\
\hline Information Technology & $\mathrm{BSc}, \mathrm{MSc}, \mathrm{MPhil}, \mathrm{PhD}$ \\
\hline Information Science / CIS & $\mathrm{MSc}, \mathrm{MPhil}, \mathrm{PhD}$ \\
\hline Information Systems & $\mathrm{MSc}, \mathrm{PhD}$ \\
\hline Informatics & $\mathrm{MSc}$ \\
\hline Information and Communication Technology & $\mathrm{MSc}$ \\
\hline
\end{tabular}

It is noted that only about 10 institutes as a whole in India offers Information Science/ Computer \& Information Science, Information Systems, Informatics, ICT based degrees. And a huge number of HEIs offers other degrees e.g. Computer Applications (MCA) is offered in about 6000 institutes.

\section{Way to Introduce IA in Indian Academics at Research Level}

As studied, there are different nomenclatures available on IT and Computing related subjects and the majority is broad areas. While Software Engineering as a branch available in some institutes as a specialized program. As far as other subfields are concerned it difficult to find out the subfields as a Major or program. Few universities offer specialization of Network and Security as PG level and there may be a possibility to offer Information Assurance as well.

Regarding the Research Degrees, the popular degrees are MPhil (Masters of Philosophy), PhD (Doctor of Philosophy); here MPhil may be offered as 1 to 2 Year program while PhD may be on 3 to 6 Years. It is worthy to note that still, universities offer these degrees with due credit on Research work leading to Thesis submission. While 
as per the international trend, the subfields may be incorporated as Major or Specializations and these are depicted in Table: 2 .

Table: 2-Possible degrees in MPhil/ PhD level with Information Assurance and allied subject

\begin{tabular}{|c|}
\hline MPhil/ PhD-Information Science (Information Assurance) \\
\hline MPhil/ PhD-Computer Science (Information Assurance) \\
\hline MPhil/ PhD-Computer Applications (Information Assurance) \\
\hline MPhil/ PhD-Information Systems (Information Assurance) \\
\hline MPhil/ PhD-Computer Engineering (Information Assurance) \\
\hline MPhil/ PhD-Software Engineering (Secure Software) \\
\hline
\end{tabular}

It is worthy to note that the branches may be offered with other allied nomenclature as well as depicted in the previous section viz.-

Information Assurance and Cyber Forensic

Information Security and Assurance

Cyber Security and Information Assurance

Information Assurance and Infrastructure Management etc

\section{Information Assurance Research based at PG}

Many universities have internationally started research focus since Masters degree and as a result, a trend is noticeable to offer the research-based Masters degree and normally it is offered as M.Sc. by Research or MS (by Research). Hence Indian Higher Educational Institute may offer the program as well in different related nomenclature as well. Few of such programs have been depicted in Table: 3 .

Table: 3- Some possible Information Assurance research-based PG Degrees

\begin{tabular}{|l|}
\hline \multicolumn{1}{|c|}{ Possible Research-based PG Degrees } \\
\hline MSc by Research Computer Science (Information Assurance) \\
\hline MSc by Research Information Technology (Information Assurance) \\
\hline MSc by Research Information Science / CIS (Information Assurance) \\
\hline MSc by Research Information Systems (Information Assurance) \\
\hline MSc by Research Informatics (Information Assurance) \\
\hline $\begin{array}{l}\text { MSc by Research Information and Communication Technology (Information } \\
\text { Assurance) }\end{array}$ \\
\hline
\end{tabular}

However, the full-fledged program by research on Information Assurance may also be offered where students only concentrated on a few courses work on Information Assurance and in-depth research work on Information Assurance. Some of the sample nomenclature and degrees may be as follows (refer Table: 4) - 
Table: 4- Some possible fully Information Assurance research based PG Degrees

\begin{tabular}{|l|}
\hline Possible Research-based PG Degrees \\
\hline MSc by Research in Information Assurance and Cyber Forensic \\
\hline MSc by Research in Information Security and Assurance \\
\hline MSc by Research in Cyber Security and Information Assurance \\
\hline MSc by Research in Information Assurance and Infrastructure Management etc \\
\hline
\end{tabular}

It is worthy to note that as in abroad rather M.Sc. degree, M.S. is common so all such degrees proposed may be offered with MS Degree. Engineering is another Computing based PG Degree available in India and thus the following style may be adopted to offer such degrees (refer Table: 5)

Table: 5- Some possible Information Assurance research-based PG Degrees Possible Research-based PG Degrees in Information Assurance

\begin{tabular}{|l|}
\hline MTech by Research in Computer Science (Information Assurance) \\
\hline MTech by Research in Information Technology (Information Assurance) \\
\hline MTech by Research in Information Systems (Information Assurance) \\
\hline MTech by Research in Software Engineering (Information Assurance) \\
\hline $\begin{array}{l}\text { MTech by Research in Information and Communication Technology (Information } \\
\text { Assurance) }\end{array}$ \\
\hline
\end{tabular}

Initially, the introduction of the program may be difficult to start due to the issues related to human resource, curriculum and skills, financial affairs, etc.

\section{Information Assurance Research based at UG}

Information Assurance as an interdisciplinary program may also be started at Bachelors degree. Internationally universities have started degrees in Information Assurance and allied nomenclatures. As far as India is concerned, no university yet offers program on Information Assurance at Bachelors level. But the degrees may be started at Bachelors level in different nomenclature and degrees and few of these with the concentration of Engineering, Science has been depicted in Table: 6 .

Table: 6- Some possible Information Assurance research-based UG Degrees

\begin{tabular}{|l|}
\hline \multicolumn{1}{|c|}{ Possible Research-based UG Degrees in Information Assurance } \\
\hline BE/BTech by Research in Computer Science (Information Assurance) \\
\hline BE/BTech by Research in Information Technology (Information Assurance) \\
\hline BS by Research in CS/ Information Technology (Information Assurance) \\
\hline B.Sc. by Research in CS/ Information Technology (Information Assurance) \\
\hline
\end{tabular}

However, it is worthy to note that at Bachelors level BCA is an important and popular degree as far as Computing field is concerned. Thus for the meritorious and interested in Information Assurance field, first of all, that specialization may be started and gradually it may be integrated with the research focused and may be offered as BCA by Research in Information Assurance. 


\section{Information Assurance Research based at Post Doctoral Level}

Apart from the PhD level, there may be potentiality to do Post Doctoral work on Information Assurance and allied field. However, one can do Post Doctoral Degrees in the field (refer Table: 7).

Table: 7- Possible Information Assurance degree at BCA level with a research focus

Possible Post Doctoral programs in Information Assurance

Post Doctoral Certificate/ Program in Information Assurance

D.Sc. in Information Assurance

D.Sc. in IT/CS (Information Assurance)

D.Litt. in Information Assurance \& Homeland Security

These programs may be offered in other related and allied nomenclature as specified previously and based on that the concentration may differ from case to case.

\section{Issues and Challenges}

The program's introduction in the field of Information assurance in India may have different challenges and issues and among these few important are include (but not limited to the following) -

- Information Assurance is an interdisciplinary and broad domain consist of different branches and field; thus the HR of the area need to learn about the different field at least basic.

- The field Information Assurance is skill-based and thus industrial interaction would be best for the healthy result.

- Information Assurance program by research can be sought with specific skill-based specializations viz. Cloud Security, Mobile Security, Web and Database Security, etc.

- The field, Information Assurance is growing rapidly but still, there is an unwillingness in academia.

- The research interest among the students is still limited but there is a requirement of creation of awareness building among the UG, PG students to do research-based IA program for the betterment of the program.

- Initially, at UG level, the Research-based Information Assurance may be difficult, hence the research focus may be started at the medium stage of UG and PG program.

\section{Conclusion with Suggestion}

Information Assurance is growing and applicable in almost all type of organizations and institutions. There is a shortage of skilled manpower in the field and thus proper initiative should be tendered for proper manpower solution in the security and privacy. The research-based Information Assurance educated would be a great product for the development of theories in security and privacy. The research-based degree holders can also be suitable for the designing and development of the policy related to the privacy, security and technological management. Information Assurance programs need to start with collaboration with other departments for a better result. There may be proper planning and initiative for the research-based Information Assurance program of introductory coursework as well in the field so that the researchers and learner can reach the goal.

\section{References}

[1] Bonner, W., \& Chiasson, M. (2005). If fair information principles are the answer, what was the question? An actor-network theory investigation of the modern constitution of privacy. Information and Organization, 15(4), 267-293.

[2] Borgesius, F. Z., Gray, J., \& van Eechoud, M. (2015). Open data, privacy, and fair information principles: Towards a balancing framework. Berkeley Technology Law Journal, 30(3), 2073-2131. 
[3] Bulgurcu, B., Cavusoglu, H., \& Benbasat, I. (2010). Information security policy compliance: an empirical study of rationality-based beliefs and information security awareness. MIS quarterly, 34(3), 523-548.

[4] Burkell, J., \& Carey, R. (2011). Personal Information and the Public Library: Compliance with Fair Information Practice Principles/Les renseignements personnels dans les bibliothèques publiques: le respect des principes d'équité dans les pratiques de collecte de renseignements. Canadian Journal of Information and Library Science, 35(1), 1-16.

[5] Cannoy, S. D., \& Salam, A. F. (2010). A framework for health care information assurance policy and compliance. Communications of the ACM, 53(3), 126-131.

[6] Chakraborty, R., Ramireddy, S., Raghu, T. S., \& Rao, H. R. (2010). The information assurance practices of cloud computing vendors. IT professional, 12(4), 29-37.

[7] Chen, Y., Ramamurthy, K., \& Wen, K. W. (2012). Organizations' information security policy compliance: Stick or carrot approach?. Journal of Management Information Systems, 29(3), 157-188.

[8] Cherdantseva, Y., \& Hilton, J. (2015). Information security and information assurance: discussion about the meaning, scope, and goals. In Standards and Standardization: Concepts, Methodologies, Tools, and Applications (pp. 1204-1235).

[9] Cooper, S., Nickell, C., Piotrowski, V., Oldfield, B., Abdallah, A., Bishop, M., ... \& Pérez, L. C. (2010). An exploration of the current state of information assurance education. ACM SIGCSE Bulletin, 41(4), 109-125.

[10] Ezingeard, J. N., McFadzean, E., \& Birchall, D. (2005). A model of information assurance benefits. Information Systems Management, 22(2), 20-29.

[11] Hamill, J. T., Deckro, R. F., \& Kloeber Jr, J. M. (2005). Evaluating information assurance strategies. Decision Support Systems, 39(3), 463-484.

[12] Höne, K., \& Eloff, J. H. P. (2002). Information security policy—what do international information security standards say? Computers \& Security, 21(5), 402-409.

[13] Knapp, K. J., Marshall, T. E., Kelly Rainer, R., \& Nelson Ford, F. (2006). Information security: management's effect on culture and policy. Information Management \& Computer Security, 14(1), 24-36.

[14] Paul, P.K., Chatterjee, D., Bhuimali, A., Atarthy, A. (2016). Cyber Crime: An Important facet for promoting Digital Humanities-A Short Review in Saudi Journal of Humanities and Social Science, 1(1), 13-16.

[15] Paul, P.K. \& Aithal, P.S. (2018). Cyber Crime: Challenges, Issues, Recommendation and Suggestion in Indian Context, International Journal of Advanced Trends in Engineering and Technology 3(1), 59-62.

[16] Paul, P.K., and Aithal P.S. (2018). Cyber Security to Information Assurance: The Changing World of Cyber Sciences in Proceedings of National Conference on Quality in Higher education challenges \& opportunities (ISBN: 978-93-5311-0826), Srinivas University, 11-18.

[17] Pérez, L. C., Cooper, S., Hawthorne, E. K., Wetzel, S., Brynielsson, J., Gökce, A. G., ... \& Philips, A. (2011, June). Information assurance education in two-and four-year institutions. In Proceedings of the 16th annual conference reports on Innovation and technology in computer science education-working group reports (pp. 39-53).

[18] Proia, A., Simshaw, D., \& Hauser, K. (2015). Consumer cloud robotics and the fair information practice principles: Recognizing the challenges and opportunities ahead. Minn. JL Sci. \& Tech., 16, 145.

[19] Rees, J., Bandyopadhyay, S., \& Spafford, E. H. (2003). A policy framework for information security. Communications of the ACM, 46(7), 101-106.

[20] Reidenberg, J. R. (1994). Setting standards for fair information practice in the US private sector. Iowa L. Rev., 80, 497.

[21] Li, Y., Stweart, W., Zhu, J., \& Ni, A. (2012). Online privacy policy of the thirty Dow Jones corporations: Compliance with FTC Fair Information Practice Principles and readability assessment. Communications of the IIMA, 12(3), 5. 